\title{
Refractory Cutaneous Melanoma
}

National Cancer Institute

\section{Source}

National Cancer Institute. Refractory Cutaneous Melanoma. NCI Thesaurus. Code C150544.

Melanoma of the skin that is resistant to treatment. 